\title{
Antioxidant role of carotenoids in Phaffia rhodozyma
}

\author{
William A. SCHROEDER and E. A. JohNSON* \\ Department of Food Microbiology and Toxicology, 1925 Willow Drive and Department of Bacteriology, \\ 1550 Linden Drive, University of Wisconsin, Madison, Wisconsin 53706, USA
}

(Received 3 September 1992; revised 13 November 1992; accepted 14 January 1993)

\begin{abstract}
The role of carotenoids in protecting the yeast Phaffia rhodozyma against reactive oxygen species was studied. Addition of the $\mathrm{O}_{2}^{-}$-generator duroquinone (DQ) to yeast-malt broth increased total carotenoid content as well as the relative amounts of xanthophylls present, while the reactive oxygen scavenger mannitol reversed this effect. Resistance to DQ increased in the stationary phase, particularly in the carotenoid-hyperproducing strain studied. Assay of superoxide dismutase (SOD) in P. rhodozyma indicated the presence of Mn-SOD and the complete absence of $\mathrm{Fe}-\mathrm{SOD}$ and $\mathrm{Cu} / \mathrm{Zn}-\mathrm{SOD}$. Catalase activity in $P$. rhodozyma was significantly lower than in Saccharomyces cerevisiae, particularly in stationary cultures. In young cells, $\mathrm{H}_{2} \mathrm{O}_{2}$ resistance was directly related to carotenoid levels, and selection of cultures based on peroxide resistance resulted in slightly increased carotenoid production. These results indicate that carotenoids play an antioxidant role during ageing in $P$. rhodozyma.
\end{abstract}

\section{Introduction}

The red fermenting yeast, Phaffia rhodozyma (Miller et al., 1976), has received considerable attention in recent years as a potential biological source of the carotenoid astaxanthin $\quad\left(3,3^{\prime}\right.$-dihydroxy- $\beta, \beta$-carotene-4,4'-dione $)$ (Andrewes et al., 1976). This interest is due to the unique role of astaxanthin in providing pigmentation to aquacultured salmonids and red sea bream. Currently, astaxanthin is produced by total chemical synthesis and its market has been estimated as $60-100$ million US dollars per year (Johnson \& An, 1991). Astaxanthin synthesized by $P$. rhodozyma could provide an alternative source if it is produced economically and satisfactorily incorporated by salmonids. Astaxanthin produced by $P$. rhodozyma is deposited in the flesh of salmonids (Johnson et al., 1980; Torrissen et al., 1989); however, wild-type isolates of the yeast are uneconomical because of their low astaxanthin production. We have attempted to increase productivity by understanding the function of carotenoids in P. rhodozyma and the development of selective procedures for increased pigmentation. Selections with antimycin A have produced yeast strains with significantly enhanced pigmentation (An et al., 1989), which may be due to a blockade of the primary

* Author for correspondence (mail should be addressed to the Department of Food Microbiology and Toxicology). Tel. (608) 263 7944; fax (608) 2631114.

Abbreviations: SOD, superoxide dismutase; HDCO, 3-hydroxy-3', 4'-didehydro- $\beta$ - $\psi$-carotene-4-one; DQ, duroquinone. respiratory chain at the $\mathrm{bc}_{1}$ complex, producing activated oxygen species such as $\mathrm{O}_{2}^{-}, \mathrm{H}_{2} \mathrm{O}_{2}$ and $\mathrm{OH} \cdot$ (Fee \& Teitelbaum, 1972) which stimulated carotenoid formation. These species have been reported to be involved in ageing in fungi (Munkres et al., 1984). Since carotenoids can be sensitive antioxidants (Burton \& Ingold, 1984; Terao, 1989), we felt that carotenoids might protect $P$. rhodozyma from oxidative injury, and this hypothesis was investigated in this study.

\section{Methods}

Chemicals. The following chemicals were obtained from Sigma: hydrogen peroxide ( $30 \%$ solution, v/v), superoxide dismutase (SOD) (from bovine erythrocytes, 15000 units $\mathrm{mg}^{-1}$ ), catalase (from bovine liver, 2500 units $\mathrm{mg}^{-1}$ ) 2,3,5,6-tetramethyl-2,5-cyclohexadiene-1,4dione (duroquinone; DQ), nitro blue tetrazolium (NBT), DMSO, acriflavine, ethidium bromide, 2,3,5-triphenyl-2H-tetrazolium chloride, succinic acid, potassium hydrogen phthalate, and all sugars except for glucose. Glucose and acetone (ACS grade) were from Fisher Scientific. Petroleum ether (residue analysis grade; boiling range $30-60^{\circ} \mathrm{C}$ ) was from EM Industries. Ethanol (200 proof; USP grade) was from USI Chemicals. BCA protein assay reagent was from Pierce Chemical. All other chemicals used were of analytical grade or the best grade commercially available.

Yeast strains and growth. The $P$. rhodozyma natural isolate (67-385) was kindly provided by Mary Miranda, University of California, Davis. AF-1 (a white mutant blocked in carotenoid biosynthesis), and the hyperproducing strains $2 \mathrm{~A} 2 \mathrm{~N}, \mathrm{MI}-1$, and anF1-P were derived from 67-385 by mutagenesis (An, 1991; An et al., 1989). Isolate 67-385 was chosen as the parent strain, owing to its relatively high pigmentation and growth. Yeasts were maintained on slants of yeast extract/malt extract/peptone/glucose medium (YM broth, Difco) with $2 \%(\mathrm{v} / \mathrm{v})$ agar $\left(\mathrm{YM}\right.$ agar) and refrigerated at $4{ }^{\circ} \mathrm{C}$. Yeast strains were also stored in $40 \%$ glycerol $/ 60 \%$ YM broth $(v / v)$ at $-70^{\circ} \mathrm{C}$. 
$P$. rhodozyma was usually grown in $\mathrm{YM}$ broth or on $\mathrm{YM}$ agar plates at $20{ }^{\circ} \mathrm{C}$. In determining sensitivity of yeast strains to $\mathrm{H}_{2} \mathrm{O}_{2}$ or $\mathrm{DQ}$, cultures were grown in $\mathrm{YM}$ broth, serially diluted in $0.85 \% \mathrm{NaCl}$ and plated onto $1 \% \mathrm{YM}$ agar supplemented with either DQ (dissolved in $0.1 \% \mathrm{DMSO} / \mathrm{YM}$ agar) or $\mathrm{H}_{2} \mathrm{O}_{2}$. All chemical additions were made to molten YM agar cooled to $39^{\circ} \mathrm{C}$ and immediately poured into plates. Survival was measured by determining the number of colonies recovered on $\mathrm{YM}$ agar with inhibitor (DQ or $\mathrm{H}_{2} \mathrm{O}_{2}$ ) compared to numbers recovered on $\mathrm{YM}$ agar without inhibitor. Growth in liquid media was measured by cell dry mass: $5 \mathrm{ml}$ liquid culture was pipetted into baked, tared $13 \times 100 \mathrm{~mm}$ disposable borosilicate tubes, which were centrifuged for $1 \mathrm{~min}$; the pellet was washed once with distilled water, and dried overnight at $115^{\circ} \mathrm{C}$.

Measurement of catalase and superoxide dismutase. Cells were harvested by centrifugation, washed and resuspended in ice cold $100 \mathrm{~mm}$-phosphate buffer ( $\mathrm{pH} \mathrm{7.0)} \mathrm{(catalase} \mathrm{assays)} \mathrm{or} \mathrm{ice} \mathrm{cold} \mathrm{distilled}$ water (SOD assays). The cells were disrupted by passage through a French press at 2000 p.s.i. at $0{ }^{\circ} \mathrm{C}$. Samples were observed by microscopy and estimated to be greater than $95 \%$ disrupted. Total cellular protein was assayed by the BCA protein assay method (Pierce). Cell-free extracts were obtained by centrifugation at $10000 \mathrm{~g}$ for $10 \mathrm{~min}$ at $0^{\circ} \mathrm{C}$. For assay of catalase (Beers \& Sizer, 1951), samples were added to a solution containing a final concentration of $10 \mathrm{~mm}$ $\mathrm{H}_{2} \mathrm{O}_{2}$ in 100 mM-phosphate buffer ( $\mathrm{pH} \mathrm{7.0)}$, and the decrease in absorbance was recorded over $30 \mathrm{~s}$ at $240 \mathrm{~nm}$ in a Gilford Response Spectrophotometer. One unit of catalase was defined as the amount of enzyme which broke down $1 \mu \mathrm{mol} \mathrm{H}_{2} \mathrm{O}_{2} \min ^{-1}$. For SOD activity stains, $350 \mu \mathrm{g}$ total cell protein in $30 \mu \mathrm{l}$ was mixed $1: 1$ with loading buffer $(20 \%$ (v/v) glycerol; $0.01 \%$ bromophenol blue loading buffer), and applied to a $6.5 \%(\mathrm{w} / \mathrm{v})$ polyacrylamide/bisacrylamide $(30: 0.8)$ non-denaturing gel $(\mathrm{pH} 8.8)$ containing a $5 \%(\mathrm{w} / \mathrm{v})$ stacking gel (pH 6.8). The gel was run at $40 \mathrm{~mA}$ constant current for 3-4h. The gels were then developed by NBT staining as described by Flohe \& Otting (1984).

Carotenoid extraction and analysis. For analysis of yeast carotenoid content, $P$. rhodozyma was grown for $5 \mathrm{~d}$ in $30 \mathrm{ml}$ liquid YM or YNB medium in $300 \mathrm{ml}$ baffled flasks shaken at 150 r.p.m. on an orbital shaker controlled at $20^{\circ} \mathrm{C}$. Liquid culture $(25 \mathrm{ml})$ was harvested and centrifuged, resuspended in about $25 \mathrm{ml}$ water, and $1 \mathrm{ml}$ of the suspension was centrifuged at 15000 r.p.m. for $5 \mathrm{~min}$ and extracted by the DMSO method (Sedmak et al., 1990). Cells were washed twice in a $5 \mathrm{ml}$ test tube with $2 \mathrm{ml}$ deionized water, and once with $1 \mathrm{ml}$ acetone; the pellets were air-dried for about $1 \mathrm{~min}$ and $1 \mathrm{ml}$ DMSO preheated to $55^{\circ} \mathrm{C}$ was added to each tube. After the addition of glass beads $(0.5 \mathrm{~mm})$, the tubes were vortexed for $20-30 \mathrm{~s}$. Acetone $(1 \mathrm{ml})$ was added to extract the carotenoid, and $1 \mathrm{ml}$ petroleum ether and $1 \mathrm{ml}$ $20 \%(\mathrm{w} / \mathrm{v}) \mathrm{NaCl}$ in water were added. The phases were separated by centrifugation for $2 \mathrm{~min}$. The petrol phase was removed and the carotenoid content determined by the $A_{474}$. Total carotenoids were calculated using $A_{1 \mathrm{~cm}}^{1 \%}=2100$. Individual carotenoids were analysed by TLC and absorption spectra as previously described by An et al. (1989).

All experiments were performed in duplicate or triplicate and replicated at least once. The error estimates presented in the text and figures for yeast mass, carotenoid content, and enzyme activities represent one standard deviation from the mean.

\section{Results}

Influence of duroquinone on survival and carotenogenesis in growing and stationary cultures

Previous studies showed that astaxanthin synthesis continued in $P$. rhodozyma after growth had terminated
(Johnson \& Lewis, 1979). The sensitivity to duroquinone, a redox-cycling quinone that generates intracellular $\mathrm{O}_{2}{ }^{-}$ (Moore et al., 1989), was determined in actively growing $(2 \mathrm{~d})$ and mature $(5 \mathrm{~d})$ cultures. Two-d-old cultures were quite sensitive to $D Q$, while 5-d-old cultures were more resistant (Fig. 1). The carotenoid hyperproducing strain $2 \mathrm{~A} 2 \mathrm{~N}$ showed the greatest increase in resistance to $\mathrm{DQ}$ during aging. DQ growth inhibition was relieved by addition of SOD to the medium (data not shown), suggesting that $\mathrm{O}_{2}^{-}$led to the growth inhibition. These results indicated a relationship between carotenoid levels and $\mathrm{O}_{2}^{-}$sensitivity in $P$. rhodozyma.

The influence of DQ on carotenogenesis was determined in a hyperproducer and the wild type. Carotenoid
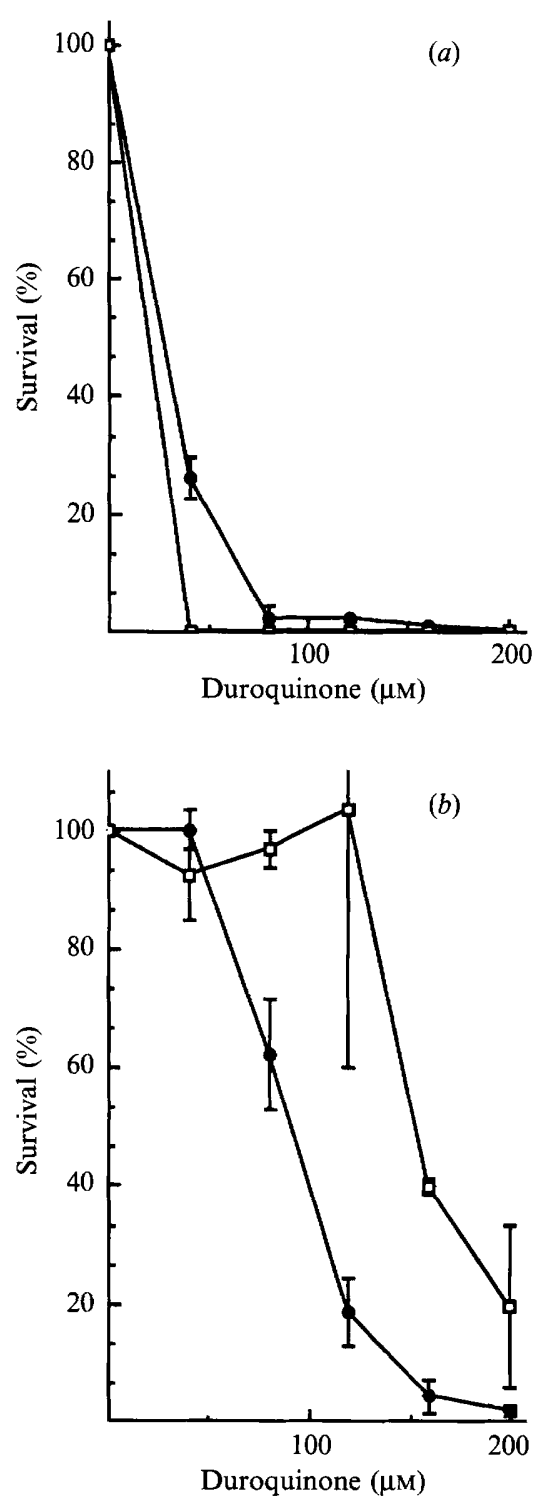

Fig. 1. Susceptibility of $P$. rhodozyma strains 67-385 (O) and $2 \mathrm{~A} 2 \mathrm{~N}$ ( $\square$ ) to duroquinone on YM agar. (a) Two-d-old cultures; (b) 5-d-old cultures. 
Table 1. Effects of duroquinone and mannitol on growth and pigmentation of $P$. rhodozyma 67-385 grown in $Y M$ broth for $5 d$

\begin{tabular}{lcc}
\hline \hline \multicolumn{1}{c}{ Addition to $\mathrm{YM}$ broth } & $\begin{array}{c}\text { Growth } \\
\left(\mathrm{mg} \mathrm{ml}^{-1}\right)\end{array}$ & $\begin{array}{c}\text { Carotenoid } \\
{\left[\mu \mathrm{g}(\mathrm{g} \text { yeast })^{-1}\right]}\end{array}$ \\
\hline None & $4 \cdot 43$ & 314 \\
Duroquinone $(100 \mu \mathrm{M})$ & $4 \cdot 56$ & 425 \\
Duroquinone $(150 \mu \mathrm{M})$ & $4 \cdot 52$ & 492 \\
Duroquinone $(100 \mu \mathrm{M})+$ mannitol & $5 \cdot 17$ & 331 \\
$\begin{array}{l}(20 \mathrm{mM}) \\
\text { Duroquinone }(100 \mu \mathrm{M})+\text { mannitol } \\
(30 \mathrm{mM})\end{array}$ & $5 \cdot 14$ & 302 \\
\hline \hline
\end{tabular}

Table 2. Effects of duroquinone and mannitol on the carotenoid composition of $P$. rhodozyma 67-385

\begin{tabular}{|c|c|c|c|}
\hline & $\begin{array}{c}\text { No } \\
\text { treatment }\end{array}$ & $\begin{array}{c}\text { Duroquinone } \\
(100 \mu \mathrm{M})\end{array}$ & $\begin{array}{c}\text { Duroquinone } \\
(100 \mu \mathrm{M}) \\
+ \text { mannitol }(30 \mathrm{mM})\end{array}$ \\
\hline \multicolumn{4}{|l|}{$\begin{array}{l}\text { Carotenoid } \\
{\left[\mu \mathrm{g}(\mathrm{g} \text { yeast) })^{-1}\right]}\end{array}$} \\
\hline $\mathrm{DCD}^{*}$ & 3 & $\mathrm{ND}$ & ND \\
\hline cis-Astaxanthin & 10 & 23 & 14 \\
\hline trans-Astaxanthin & 177 & 380 & 273 \\
\hline Phoenicoxanthin & 6 & ND & ND \\
\hline $\mathrm{HDCO}$ & 16 & 69 & 64 \\
\hline Torulene & 22 & 57 & 27 \\
\hline $\begin{array}{l}\text { 3-Hydroxy- } \\
\text { echinenone }\end{array}$ & 19 & 29 & 32 \\
\hline$\gamma$-Carotene & 16 & 6 & 23 \\
\hline$\beta$-Zeacarotene & 3 & ND & ND \\
\hline$\beta$-Carotene & 35 & 6 & 14 \\
\hline Others & 10 & 6 & 9 \\
\hline $\begin{array}{l}\text { Total } \\
{\left[\mu \mathrm{g}(\mathrm{g} \text { yeast })^{-1}\right]}\end{array}$ & 317 & 576 & 456 \\
\hline Growth (mg ml-1) & $2 \cdot 8$ & $3 \cdot 2$ & $3 \cdot 5$ \\
\hline
\end{tabular}

* DCD, 3,3'-dihydroxy- $\beta$ - $\gamma$-carotene-4,4'-dione (An, 1991). ND, not determined, because of low content $(<1 \%)$.

formation in the hyperproducing mutant anF-1P increased by $50 \%$ from $1100 \mu \mathrm{g} \mathrm{g}^{-1}$ to $1650 \mu \mathrm{g} \mathrm{g}^{-1}$ in $\mathrm{YM}$ broth containing $100 \mu \mathrm{M}-\mathrm{DQ}$ added during the exponential phase (data not shown). Growth in the wild-type strain $67-385$ was unaffected by $150 \mu \mathrm{M}-\mathrm{DQ}$ but carotenoid production increased by about $60 \%$ (Table 1). Carotenoid production was significantly decreased when mannitol was added to DQ incubation (Tables 1 and 2). These results suggested that activated oxygen species stimulated carotenoid synthesis in the yeast.

Yeasts treated with DQ $(100 \mu \mathrm{M})$ or DQ $(100 \mu \mathrm{M})$ plus mannitol $(30 \mathrm{mM})$ were analysed for carotenoid composition. DQ increased the proportions of the major xanthophylls [astaxanthin, HDCO (3-hydroxy$3^{\prime}-4^{\prime}$-didehydro- $\beta$ - $\psi$-carotene-4-one), and 3-hydroxy-
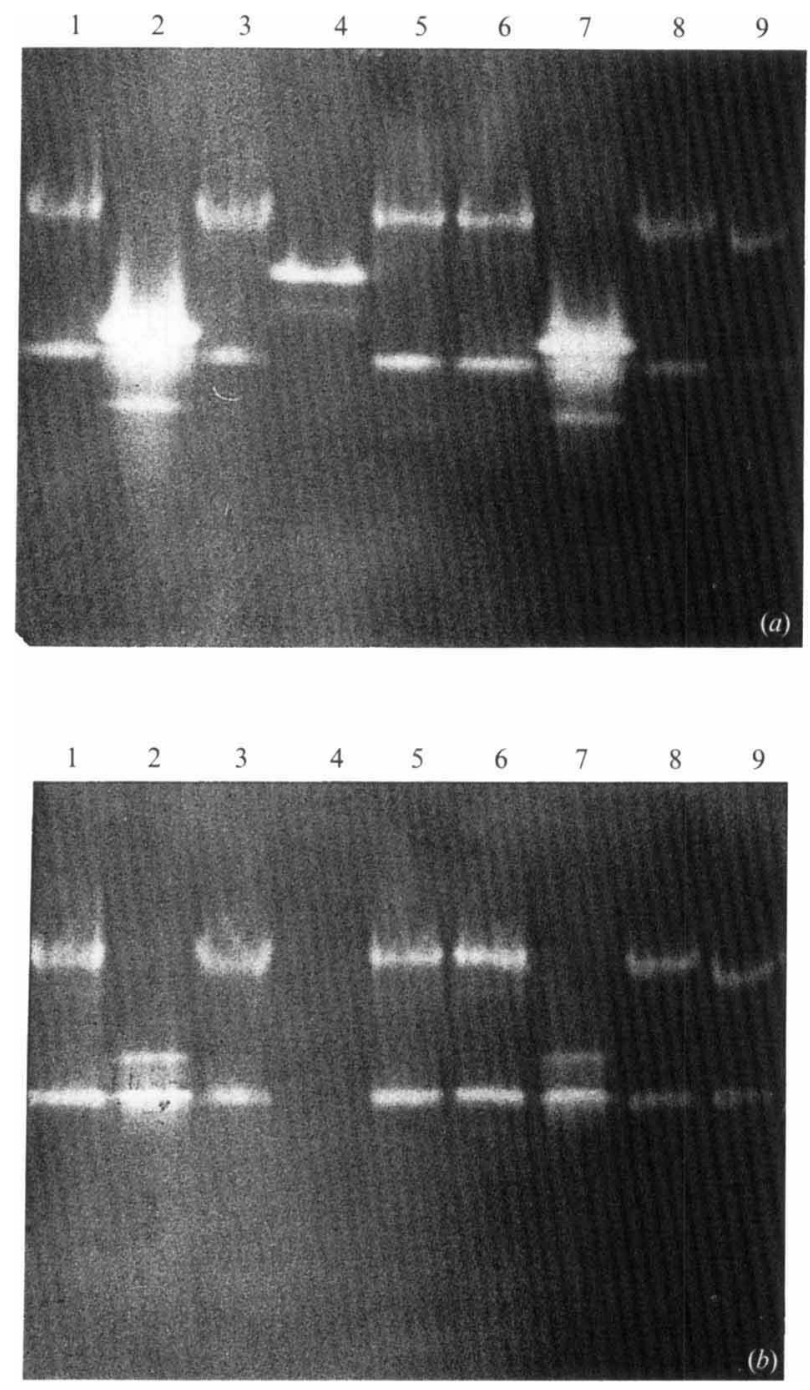

Fig. 2. Polyacrylamide electrophoresis gel stained for SOD activity from $P$. rhodozyma and $S$. cerevisiae grown for $5 \mathrm{~d}$ in YM broth. (a) Gel stained in the absence of $\mathrm{KCN}$; $(b)$ gel stained in the presence of $\mathrm{KCN}$. Lanes: $1, P$. rhodozyma hyperproducing strain MI-1; 2, S. cerevisiae; 3 , wild-type $P$. rhodozyma strain $67-385 ; 4$, commercial bovine $\mathrm{Cu} / \mathrm{Zn}$ -

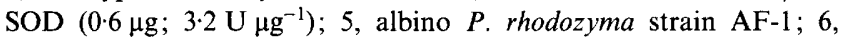
hyperproducing $P$. rhodozyma strain $2 \mathrm{~A} 2 \mathrm{~N} ; 7, S$. cerevisiae (duplicate); 8 , wild-type strain 67-385 (duplicate); 9 , hyperproducing strain MI-1 (duplicate).

echinenone] but decreased the proportions of major carotenes $(\beta$-carotene and $\gamma$-carotene (Table 2$)$. The addition of mannitol together with DQ resulted in a decreased proportion of xanthophylls and an increased proportion of carotenes (Table 2).

\section{Superoxide dismutase (SOD) activity in P. rhodozyma}

Since resistance to duroquinone varied between wildtype and mutant $P$. rhodozyma strains, SOD activity was assayed in four strains (the albino strain AF-1, 67-385, $2 \mathrm{~A} 2 \mathrm{~N}$ and a second hyperproducing strain $\mathrm{MI}-1$ ) and in 

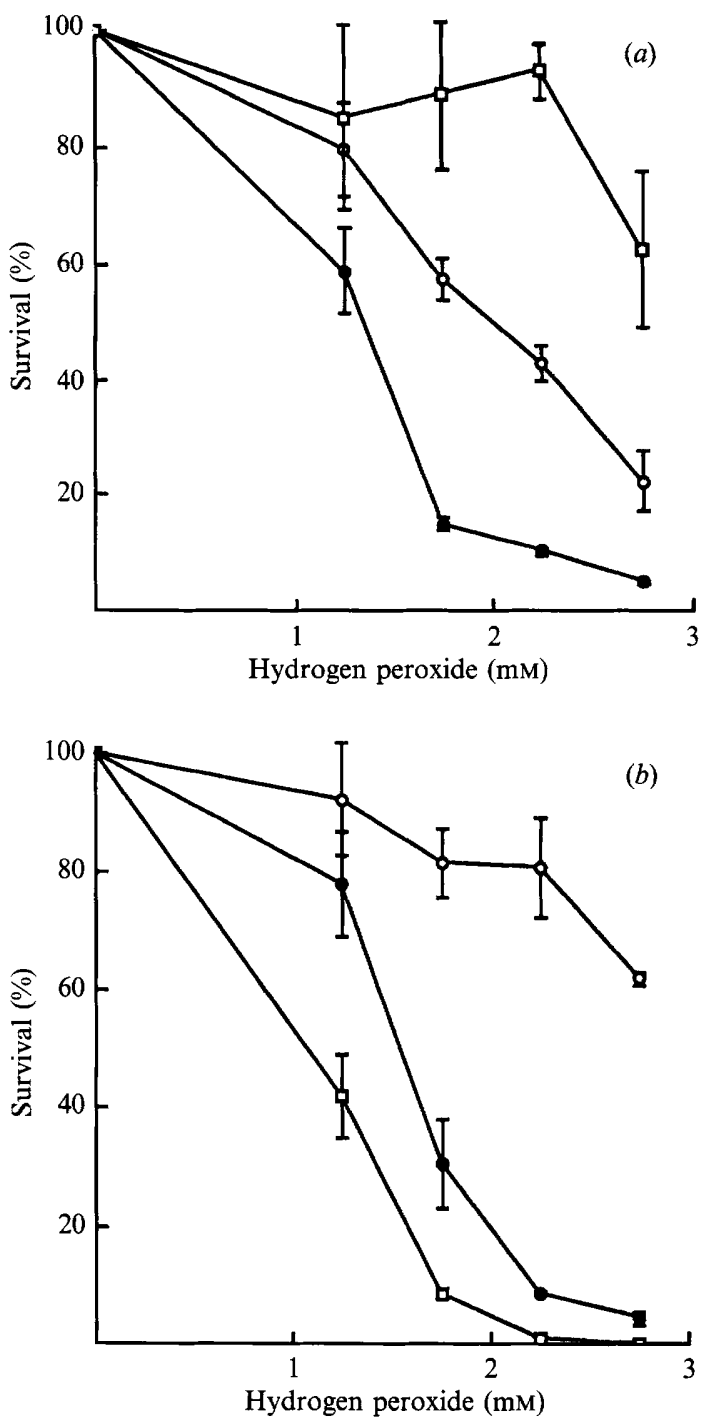

Fig. 3. Susceptibility of $P$. rhodozyma strains $67-385(0)$ and $2 \mathrm{~A} 2 \mathrm{~N}$ $(\square)$ and $S$. cerevisiae $(\mathrm{O})$ to $\mathrm{H}_{2} \mathrm{O}_{2}$ on $\mathrm{YM}$ agar. (a) Two-d-old cultures; (b) 5-d-old cultures.

$S$. cerevisiae by activity staining of electrophoresis gels. SOD levels did not appear to differ among the four strains (Fig. 2), and its activity was not changed in cells grown in the presence of duroquinone, nor did it change as a function of culture age (data not shown). Interestingly, SOD activity in $P$. rhodozyma was resistant to both $\mathrm{KCN}(10 \mathrm{mM})$ and $\mathrm{H}_{2} \mathrm{O}_{2}(5 \mathrm{mM})$. This indicated a lack of $\mathrm{Cu} / \mathrm{Zn}$-SOD $\left(\mathrm{CN}^{-}\right.$-sensitive $)$and $\mathrm{Fe}$-SOD $\left(\mathrm{H}_{2} \mathrm{O}_{2^{-}}\right.$sensitive) and the presence of only Mn-SOD (insensitive to $\mathrm{H}_{2} \mathrm{O}_{2}$ and $\mathrm{CN}^{-}$) Multiple bands of activity were observed, possibly indicating aggregates or isozymes of Mn-SOD in $P$. rhodozyma. Since it has been reported that Mn-SOD is present only in the mitochondria (Moore et al., 1989), carotenoids may be important in protecting against extramitochondrial oxidative stress. The related carotenogenic yeast, Rhodotorula muci-

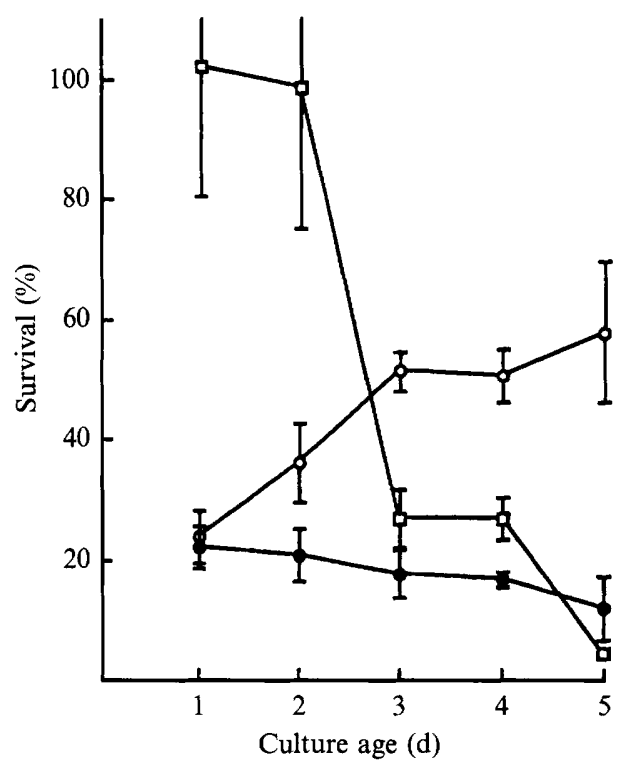

Fig. 4. Effect of culture age on susceptibility of $P$. rhodozyma strains $67-385(\bigcirc)$ and $2 \mathrm{~A} 2 \mathrm{~N}(\square)$ and $S$. cerevisiae (O) to $2 \mathrm{mM}-\mathrm{H}_{2} \mathrm{O}_{2}$ on YM agar.

laginosa, also has been reported to contain only Mn-SOD (Moore et al., 1989).

$\mathrm{H}_{2} \mathrm{O}_{2}$ resistance and catalase activity in $\mathrm{P}$. rhodozyma

Since $\mathrm{O}_{2}^{-}$can be converted in vitro to $\mathrm{H}_{2} \mathrm{O}_{2}$ by superoxide dismutase:

$$
\mathrm{O}_{2}^{-}+\mathrm{O}_{2}^{-}+2 \mathrm{H}^{+} \rightarrow \mathrm{H}_{2} \mathrm{O}_{2}+\mathrm{O}_{2}
$$

we examined whether strains of $P$. rhodozyma that differed in sensitivity to duroquinone showed the same pattern of sensitivity to $\mathrm{H}_{2} \mathrm{O}_{2}$. Unexpectedly, the pattern was opposite and the hyperproducing strain $2 \mathrm{~A} 2 \mathrm{~N}$ was most resistant in exponential-phase growth and yet more sensitive in stationary phase compared to the wild-type strain 67-385 (Fig. 3). The drop in resistance to $\mathrm{H}_{2} \mathrm{O}_{2}$ at the onset of stationary phase was particularly large in the hyperproducing strain $2 \mathrm{~A} 2 \mathrm{~N}$ (Fig. 3). Because of the decreased resistance of $2 \mathrm{~A} 2 \mathrm{~N}$ to $\mathrm{H}_{2} \mathrm{O}_{2}$ in older cultures, sensitivity to $2 \mathrm{mM}-\mathrm{H}_{2} \mathrm{O}_{2}$ was followed throughout the course of $5 \mathrm{~d}$ fermentation with $2 \mathrm{~A} 2 \mathrm{~N}, 67-385$ and $S$. cerevisiae (Fig. 4). Although the resistance of 67-385 was relatively constant, the resistance of $2 \mathrm{~A} 2 \mathrm{~N}$ dropped significantly on entering the stationary phase.

We examined whether catalase activity differed in $67-385$ and $2 \mathrm{~A} 2 \mathrm{~N}$ as a function of culture age. In both strains, an age dependence was found in which catalase activity increased from approximately $5 \mathrm{U}(\mathrm{mg} \text { protein })^{-1}$ during the exponential phase to approximately $15 \mathrm{U} \mathrm{mg}^{-1}$ in the stationary phase (Fig. 5). The derepression of catalase activity was relatively small compared to that observed in S. cerevisiae (Fig. 5). 


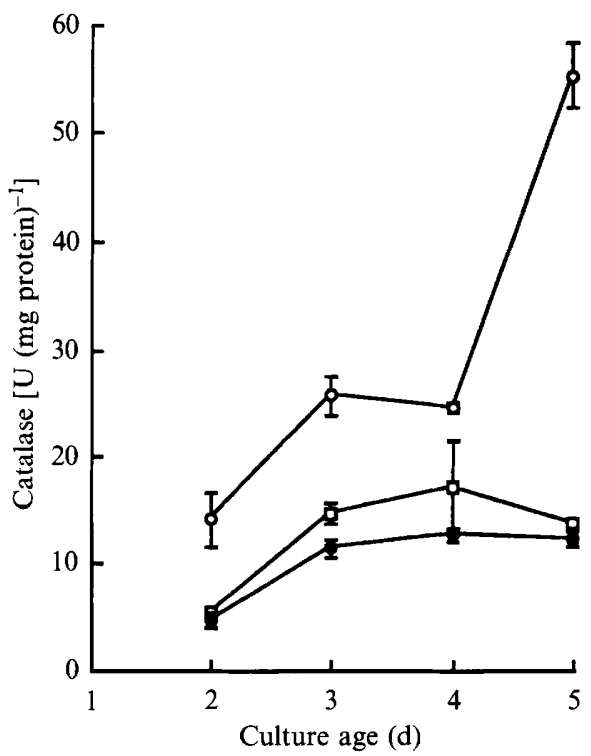

Fig. 5. Effect of culture age on catalase activity in $P$. rhodozyma strains 67-385 (O) and 2A2N ( $\square$ ) and S. cerevisiae $(O)$ grown in YM broth

Table 3. Effect of $\mathrm{H}_{2} \mathrm{O}_{2}$ on carotenogenesis and growth in P. rhodozyma 67-835

Results are means $\pm S D$.

\begin{tabular}{cccc}
\hline \hline $\begin{array}{c}\text { Time(s) of } \\
\text { addition of } \\
2 \mathrm{mM}^{-} \mathrm{H}_{2} \mathrm{O}_{2}(\mathrm{~h})\end{array}$ & $\begin{array}{c}\text { Carotenoid } \\
\left(\mu \mathrm{g} \mathrm{g}^{-1}\right)\end{array}$ & $\begin{array}{c}\text { Growth } \\
\left(\mathrm{mg} \mathrm{ml}^{-1}\right)\end{array}$ & $\begin{array}{c}\text { Productivity* } \\
\left(\mu \mathrm{g} \mathrm{ml}^{-1}\right)\end{array}$ \\
\hline Not added & $428 \pm 3$ & $4 \cdot 9 \pm 0 \cdot 1$ & $2 \cdot 11 \pm 0 \cdot 04$ \\
0 & $518 \pm 39$ & $4 \cdot 7 \pm 0 \cdot 4$ & $2 \cdot 41 \pm 0 \cdot 04$ \\
24 & $482 \pm 29$ & $4 \cdot 8 \pm 0 \cdot 3$ & $2 \cdot 31 \pm 0 \cdot 03$ \\
$0+24$ & $461 \pm 5$ & $5 \cdot 5 \pm 0 \cdot 2$ & $2 \cdot 55 \pm 0 \cdot 11$ \\
\hline
\end{tabular}

${ }^{*}$ Productivity $=$ Growth $\times$ Carotenoid

S. cerevisiae was also found to have significantly higher catalase activity than $P$. rhodozyma throughout growth, particularly after $5 \mathrm{~d}$ (Fig. 5). The sensitivity of $S$. cerevisiae to $\mathrm{H}_{2} \mathrm{O}_{2}$ was intermediate relative to the $P$. rhodozyma strains examined. These data suggest that catalase activity could not explain the pattern of sensitivity to $\mathrm{H}_{2} \mathrm{O}_{2}$ in $P$. rhodozyma. In contrast, $\mathrm{H}_{2} \mathrm{O}_{2}$ sensitivity in $\mathrm{S}$. cerevisiae correlated with catalase activity and is probably attributable to the activity of this enzyme.

Since 2A2N had higher resistance to $\mathrm{H}_{2} \mathrm{O}_{2}$ than 67-385 in young cultures, a positive selection for increased $\mathrm{H}_{2} \mathrm{O}_{2}$ resistance was attempted with 67-385. This protocol involved successively subculturing 67-385 every $48 \mathrm{~h}$ in YM media and exposing them to various $\mathrm{H}_{2} \mathrm{O}_{2}$ challenges. This protocol gave colonies with increased pigmentation $(10-20 \%$ increase in productivity after 5 passages) (Table 3). These results support the concept that carotenoids are providing a protective antioxidant role in $P$. rhodozyma.

\section{Discussion}

Carotenoid formation in $P$. rhodozyma is stimulated by antimycin and light (An \& Johnson, 1990). Many lightderepressible genes, including those regulating carotenogenesis in fungi, require molecular oxygen and a photosensitive pigment in addition to blue light for activation. Generally, these genes are induced when conditions favour the formation of activated oxygen species (Hoober \& Phinney, 1988). From the results of the present study, it seems plausible that light-regulated carotenoid biosynthesis in $P$. rhodozyma could be induced by a mechanism involving activated oxygen species.

We have found that carotenoid content in $P$. rhodozyma changes in conditions that would alter the level of intracellular activated oxygen species. The mechanism by which these species affect carotenoid levels is not presently known. It is possible that active oxygen species inhibit or destroy biosynthetic enzymes that utilize acetyl-CoA or other common precursors which are needed for carotenoid synthesis. Alternatively, they may induce, activate, or serve as substrates for enzymes involved in carotenoid formation. P. rhodozyma produces several oxygenated carotenoids, including DCD and HDCO, and these were postulated as intermediates in the biosynthesis of astaxanthin by two pathways (Johnson \& An, 1991). However, we have recently found that incubating washed $P$. rhodozyma cells in buffer with $\mathrm{H}_{2} \mathrm{O}_{2}$ resulted in the formation of DCD and an unidentified oxygenated carotenoid, and a corresponding decrease in astaxanthin and HDCO (data not shown). These results suggest that certain carotenoids, including some of those previously postulated as biosynthetic intermediates, may actually be oxidative degradation products. Our laboratory is investigating this further.

In contrast to certain other yeasts including $S$. cerevisiae, $P$. rhodozyma appears to contain only $\mathrm{Mn}$ $\mathrm{SOD}$ and lacks cytosolic $\mathrm{Cu} / \mathrm{Zn}-\mathrm{SOD}$ and Fe-SOD. The related yeast Rhodotorula mucilaginosa also possesses only Mn-SOD, which is located exclusively in the mitochondria (Moore et al., 1989). In S. cerevisiae, deletion of a gene encoding SOD made the yeast hypersensitive to oxygen (Van Loon et al., 1986). Owing to the absence of cytosolic SOD in $P$. rhodozyma, carotenoids may compensate for $\mathrm{Cu} / \mathrm{Zn}$-SOD and $\mathrm{Fe}$ $\mathrm{SOD}$ in providing antioxidant protection.

Carotenoids may also serve their antioxidant role by reacting directly with peroxyl radicals (Kennedy \& Liebler, 1992; Krinsky, 1992), providing antioxidant protection in the cytoplasm and in lipid membranes. We have found that $P$. rhodozyma contains relatively low catalase activity compared to $S$. cerevisiae, particularly 
in the stationary phase. $P$. rhodozyma underwent marked changes in resistance to $\mathrm{O}_{2}^{-}$and $\mathrm{H}_{2} \mathrm{O}_{2}$ during transition to stationary phase, the period when astaxanthin production is at its highest. These aging cells may have a high demand for antioxidants to sustain viability and astaxanthin has been postulated to be a more effective antioxidant than $\beta$-carotene (Terao, 1989). Studies in our laboratory have shown that respiration shifts from cyanide-sensitive to cyanide-insensitive as $P$. rhodozyma enters into stationary phase. Cyanide-insensitive respiration has been associated with the production of superoxide radicals (Sohal et al., 1988). In Nicotiana tabacum, it has been suggested that the intracellular ratio of $\mathrm{O}_{2}^{-}$to $\mathrm{H}_{2} \mathrm{O}_{2}$ is the major determinant of the degree of intracellular oxidative damage. The presence of the two oxygen species will allow the Haber-Weiss reaction to occur in the presence of transition metals such as iron or copper with the consequent formation of hydroxyl radicals (Bowler et al., 1991):

$$
\mathrm{H}_{2} \mathrm{O}_{2}+\mathrm{O}_{2}^{-} \rightarrow \mathrm{OH} \cdot+\mathrm{OH}^{-}+\mathrm{O}_{2}
$$

Control of the balance of the two oxygen species in the various compartments of the eukaryotic cell appears to be particularly important in preventing oxidative damage.

Carotenoids and $\mathrm{O}_{2}^{-}$do not directly react with each other without the involvement of a more reactive oxygen intermediate such as hydroxyl radical (Krinsky, 1992). In the present study, the intracellular levels of carotenoids were increased by the $\mathrm{O}_{2}^{-}$-generator duroquinone. Preliminary data indicate that $\mathrm{H}_{2} \mathrm{O}_{2}$ reacts with carotenoids giving oxidative degradation products. This suggests a mechanism for antioxidant protection by carotenoids in $P$. rhodozyma. $\mathrm{O}_{2}^{-}$induces the formation of carotenoids which are then available to react with $\mathrm{H}_{2} \mathrm{O}_{2}$, altering the ratio of $\mathrm{O}_{2}^{-}$to $\mathrm{H}_{2} \mathrm{O}_{2}$ and minimizing the production of $\mathrm{OH}$. In summary, carotenoids produced in $P$. rhodozyma may function, together with SOD and catalase, to preserve viability in the face of continued production of oxygen radicals in ageing cells.

We thank Keng-Wei Chang, June F. M. Parreiras, Gil-Hwan An and Tracey Baas for assistance with certain experiments. This work was supported by Biocolours I/S, Copenhagen, Denmark and Tulln, Austria, and by the College of Agricultural and Life Sciences, University of Wisconsin, Madison, Wisconsin. W. S. has been supported by a Wisconsin Alumni Research Foundation Fellowship and by a National Science Foundation Fellowship.

\section{References}

AN, G.-H. (1991). Improved astaxanthin production from the red yeast Phaffia rhodozyma. PhD thesis, University of Wisconsin, Madison, WI.
AN, G.-H. \& Johnson, E. A. (1990). Influence of light on growth and pigmentation of the yeast Phaffia rhodozyma. Antonie van Leeuwenhoek 57, 191-203.

AN, G.-H., Schuman, D. B. \& Johnson, E. A. (1989). Isolation of Phaffia rhodozyma mutants with increased astaxanthin content. Applied and Environmental Microbiology 55, 116-124.

Andrewes, A. G., Phaff, H. J. \& Starr, M. P. (1976). Carotenoids of Phaffia rhodozyma, a red-pigmented fermenting yeast. Phytochemistry 15, 1003-1007.

BEERS, R. F., JR \& SIZER, I. W. (1951). A spectrophotometric method for measuring the breakdown of hydrogen peroxide by catalase. Journal of Biological Chemistry 195, 133-140.

Bowler, C., Slooten, L., Vandenbranden, S., De Rycke, R., Botterman, J., Sybesma, C., Van Montagu, M. \& Inze, D. (1991). Manganese superoxide dismutase can reduce cellular damage mediated by oxygen radicals in transgenic plants. EMBO Journal 10, $1723-1732$

Burton, G. W. \& INGOLD, K. U. (1984). $\beta$-Carotene: an unusual type of lipid antioxidant. Science 224, 569-573.

FeE, J. A. \& Teitelbaum, H. D. (1972). Evidence that superoxide dismutase plays a role in protecting red blood cells against peroxidative hemolysis. Biochemical and Biophysical Research Communications 49, 180-183.

FlOHE, L. \& OTTING, F. (1984). Superoxide dismutase assays. Methods in Enzymology 105, 93-104.

HoOber, J. K. \& PhinNey, D. G. (1988). Are 'light-derepressible' genes controlled by metal-protein complexes? Trends in Biochemical Sciences 13, 371-374.

JoHnson, E. A. \& AN, G.-H. (1991). Astaxanthin from microbial sources. Critical Reviews in Biotechnology 11, 297-326.

JoHnson, E. A. \& LewIS, M. J. (1979). Astaxanthin formation by the yeast Phaffia rhodozyma. Journal of General Microbiology 115, 173-183.

Johnson, E. A., Villa, T. G. \& Lewis, M. J. (1980). Phaffia rhodozyma as an astaxanthin source in salmonid diets. Aquaculture 20, 123-134.

KeNNEDY, T. A. \& LiebleR, D. C. (1992). Peroxyl radical scavenging by $\beta$-carotene in lipid bilayers. Journal of Biological Chemistry 267, 4658-4663.

KRINSKY, N. I. (1992). Mechanism of action of biological antioxidants. Proceedings of the Society for Experimental Biology and Medicine 200, 248-254.

Miller, M. W., Yoneyama, M. \& Soneda, M. (1976). Phaffia, a new yeast genus in the Deuteromycotina (Blastomycetes). International Journal of Systematic Bacteriology 26, 286-291.

MoOre, M. M., BreEdVELd, M. W. \& AUTOR, A. P. (1989). The role of carotenoids in preventing oxidative damage in the pigmented yeast, Rhodotorula mucilaginosa. Archives of Biochemistry and Biophysics 270, 419-431.

Munkres, K. D., Rana, R. S. \& Goldstein, E. (1984). Genetically determined conidial longevity is positively correlated with superoxide dismutase, catalase, glutathione peroxidase, cytochrome $c$ peroxidase, and ascorbate free radical reductase activities in Neurospora crassa. Mechanisms of Ageing and Development 24, 83-100.

Sedmak, J. J., WeERAsinghe, D. K. \& Jolly, S. O. (1990). Extraction and quantitation of astaxanthin from Phaffia rhodozyma. Biotechnology Techniques 4, 107-112.

Sohal, R. S., Allen, R. G. \& Nations, C. (1988). Oxidative stress and cellular differentiation. Annals of the New York Academy of Sciences $551,59-75$.

TERAO, J. (1989). Antioxidant activity of $\beta$-carotene-related carotenoids in solution. Lipids 24, 659-661.

Torrissen, O. J., Hardy, R. W. \& Shearer, K. D. (1989). Pigmentation of salmonids: Carotenoid deposition and metabolism. Reviews in Aquatic Sciences 1, 209-225.

Van Loon, A. P. G. M., Pesold-Hurt, B. \& Schatz, G. (1986). A yeast mutant lacking mitochondrial manganese-superoxide dismutase is hypersensitive to oxygen. Proceedings of the National Academy of Sciences of the United States of America 83, 3820-3824. 